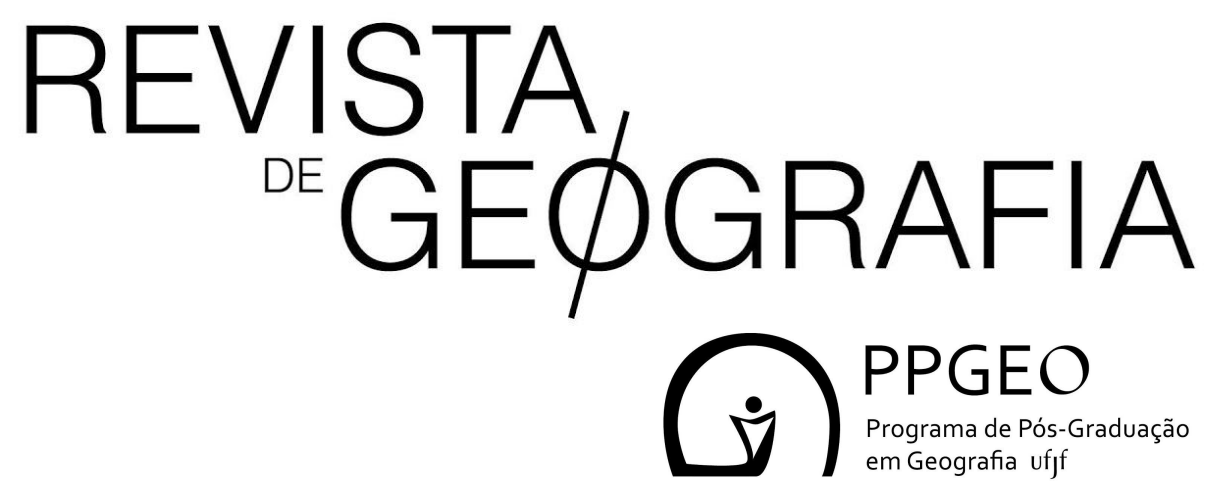

\title{
SÉRIE HISTÓRICA DO USO E OCUPAÇÃO DA TERRA NO MUNICÍPIO DE CACEQUI - RS DE 1986 A 2016
}

HISTORICAL SERIES OF THE LAND USE AND OCCUPATION IN MUNICIPALITY OF CACEQUI - RS FROM 1986 TO 2016 Av. Roraima, $n^{\circ}$ 1000, Prédio 17, sala 1113c, Camobi, Santa Maria, CEP: 97105-900 


\begin{abstract}
Resumo
A intensa ocupação humana do meio ambiente gera uma grande diversidade de usos da terra, cada qual com as suas interações com os processos naturais. Desta forma, torna-se necessário o estudo dos usos da terra e sua dinâmica ao longo do tempo. Para tanto no município de Cacequi foi realizada a análise da série histórica entre os anos de 1986 a 2016. Para a avaliação do uso da terra foram utilizadas imagens de satélite das séries LANDSAT 5 e 8 . As imagens foram escolhidas de acordo com a cobertura de nuvens do local referente aos anos de 1986, 2001 e 2016. Foi realizado uma classificação supervisionada, através do método Maxver, e definidas seis classes de uso da terra. Observou-se primeiramente um domínio de lavouras no ano de 1986, posteriormente, no ano de 2001 houve uma modificação da dinâmica de ocupação para um predomínio de campos bem como no ano de 2016. Desta forma observou-se uma forte dinâmica do uso da terra em Cacequi neste período estudado e que os processos erosivos, recorrentes na região, respondem de maneiras diferentes em formas de uso distintos. Portanto, o estudo se mostra importante para o planejamento e ordenamento territorial de Cacequi.
\end{abstract}

Palavras-chave: Sensoriamento Remoto; SIG; uso e ocupação da terra.

\begin{abstract}
The intense human occupation of the environment generates a great diversity of land uses, each with its interactions with natural processes. Thus, the study of land uses and its dynamics over time becomes necessary. For this purpose, in the city of Cacequi, the historical series was analyzed from 1986 to 2016. For land use evaluation, LANDSAT 5 and 8 series satellite images were used. The images were chosen according to the cloud cover of the site for the years 1986, 2001 and 2016. A supervised classification was performed using the Maxver method and six land use classes were defined. Firstly, a domain of tillage was observed in 1986, later in 2001 there was a change in the occupation dynamics for a predominance of fields as well as in 2016. Thus, there was a strong dynamics of land use in Cacequi during this study period and that the recurrent erosive processes in the region respond differently in different forms of use. Therefore, the study shows as important for the planning and territorial planning of Cacequi.
\end{abstract}

Key-words: Remote sensing; GIS; land use and occupation.
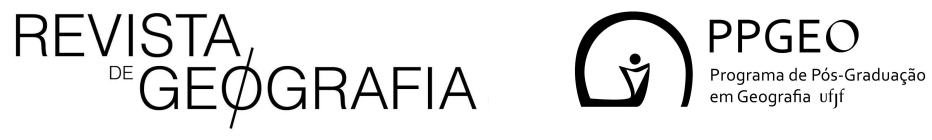

ISSN: 2236-837X35 


\section{Introdução}

Devido à intensa antropização do espaço, surgem diversas formas de uso e ocupação do meio, causando variados impactos ambientais e sociais. Em vista disto, têm-se desenvolvido diversas ferramentas de análise do uso da terra através de sensoriamento remoto e Sistemas de Informação Geográfica (SIG), para assim compreender a sua dinâmica ao longo do tempo e possibilitar o planejamento e o ordenamento territorial.

Destacam assim Souza e Reis (2011) em seu estudo no município de lbiá - MG, que a utilização de softwares de geoprocessamento e de técnicas de sensoriamento remoto para fins de mapeamento da ocupação da terra se mostram eficazes no monitoramento de mudanças ocorridas na paisagem e deste modo, podem e devem ser utilizados para fins de planejamento e gestão do território.

Quanto ao uso do sensoriamento remoto para a análise do uso e ocupação terra Teotia et al. (2009) constatam que o advento do sensoriamento remoto surgiu como uma alternativa viável, técnica e econômica, para levantamento e classificação de cobertura vegetal e uso da terra, pois alia a rapidez e precisão a um custo relativamente baixo. Ainda, Souza et al. (2014) salientam que este tipo de levantamento e análise de determinada área a partir do uso de imagens de satélite é atualmente um instrumento imprescindível para estudos ambientais, uma vez que possibilita relacionar a situação da cobertura do solo com os processos sociais e econômicos de determinado ambiente e assim possibilita seu melhor gerenciamento e planejamento.

Portanto a análise temporal da cobertura e ocupação da terra em determinada região permite observar e analisar as principais dinâmicas da ocupação do meio ambiente e as suas consequências ambientais. Desta forma é possível obter um diagnóstico mais preciso da apropriação antrópica e seus impactos gerados no meio.

O município de Cacequi está localizado na região sudoeste do estado do Rio Grande do Sul (Figura 1), estando inserido no compartimento geomorfológico da Depressão Periférica do Rio Grande do Sul (CARRARO, 1974) da qual se encontram os litótipos da sequência da Bacia Sedimentar do Paraná. Faz limite ao Norte com os municípios de São Vicente do Sul e São Pedro do Sul, a Oeste com Alegrete, a Leste com Dilermando de Aguiar e ao Sul com Rosário do Sul e São Gabriel.
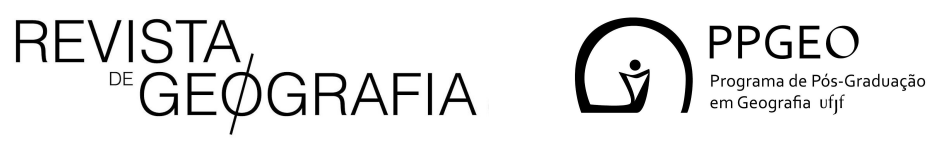


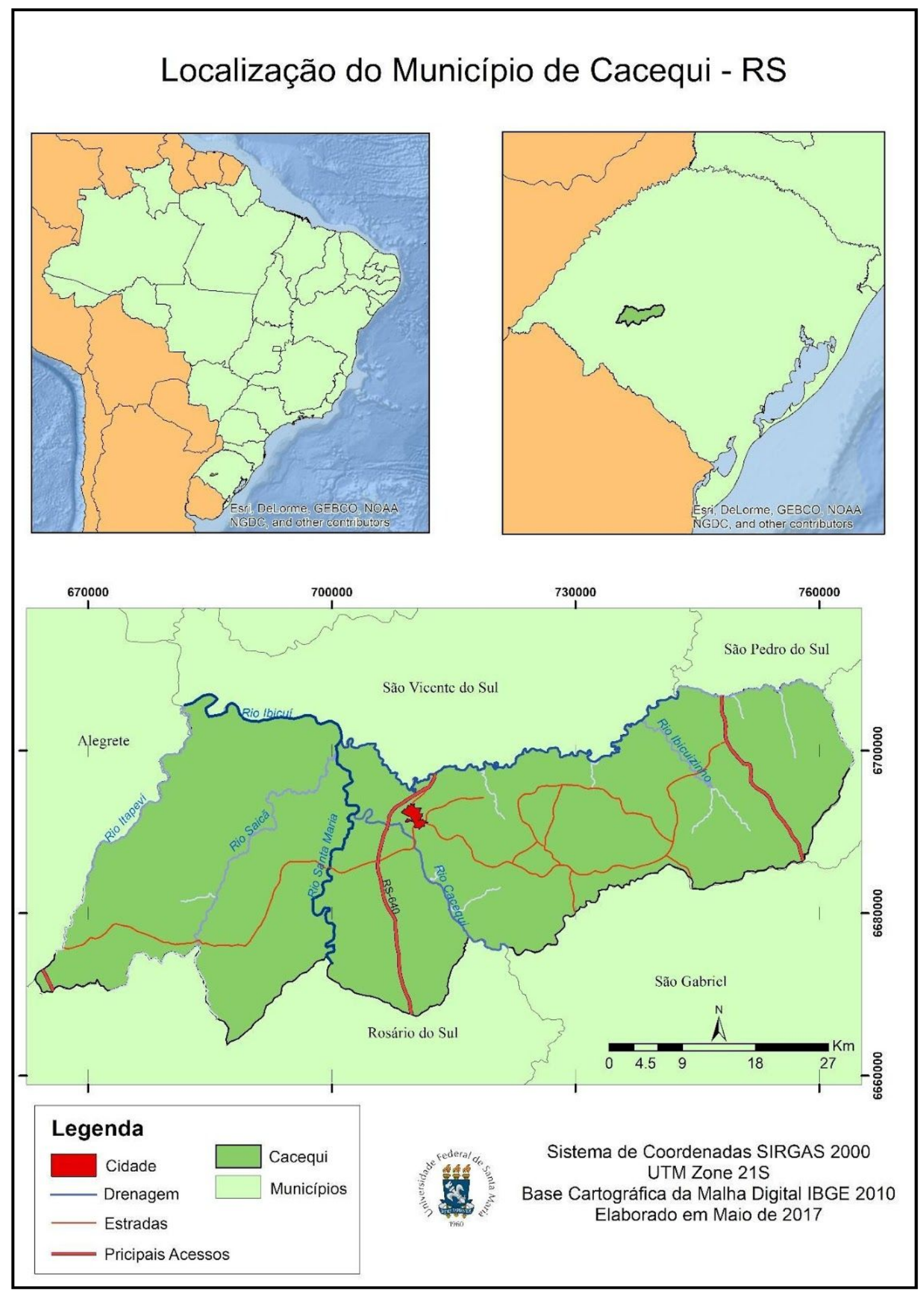

Figura 1 - Mapa de localização do município de Cacequi. Fonte: Elaborado pelos autores (2019).

Esta porção sudoeste do Rio Grande do Sul possui solos bastante frágeis e suscetíveis a erosão, e assim como destaca Suertegaray (1995) apresenta grande fragilidade ambiental, decorrente de um paleoambiente semiárido ou semi-úmido estepário que, mais recentemente, 
sofreu umidificação. Portanto a maneira como é realizada a apropriação antrópica deste meio interfere diretamente nos problemas ambientais da região.

A partir das décadas de 70 e 80 houve uma intensa mecanização do campo e consequentemente uma implantação de novas culturas, principalmente das monoculturas da soja e arroz. Esta mecanização permitiu a ocupação de novas áreas para lavouras, e a análise histórica do uso da terra possibilita a verificação da maneira como ocorreu este fenômeno em Cacequi, identificando a sua dinâmica no município.

Portanto com o uso intensivo do solo e a ampliação das áreas de lavouras, há um aumento do revolvimento do material pedológico e ainda períodos na entressafra onde o solo fica exposto. Estes fatores acabam contribuindo para a maior ocorrência dos processos erosivos e maior intensidade dos mesmos, se caracterizando como um dos grandes passivos ambientais da área de estudo.

Desta forma o presente trabalho tem por objetivo analisar a série história do uso da terra no município de Cacequi, através do uso do sensoriamento remoto identificando a sua dinâmica no período entre os anos de 1986 e 2016.

\section{Metodologia}

O estudo de uso e ocupação foi elaborado através de imagens de satélite com os Sensores TM e OLI das séries LANDSAT 5 e 8, respectivamente. Foram realizados três diferentes mapas de uso da terra, buscando entender as transformações no espaço do município. Deste modo, foi realizado uma série histórica de 30 anos, com um intervalo de 15 anos entre as imagens obtidas.

As imagens da série histórica foram escolhidas de acordo com a cobertura de nuvens do local e são datadas de 06/11/1986, 17/12/2001 e 24/11/2016. Considera-se que a órbita do satélite que cobre o município é a 223 e o ponto é 81 . As imagens do LANDSAT foram obtidas do site glovis.usgs.gov, com processamentos nível L2, ou seja, com ortorretificação espacial e correção atmosférica.

No mapa referente ao ano de 1986 foram utilizadas seis classes para a elaboração do mapa: água que é constituída pelos reservatórios de água do município e as principais drenagens; área urbana que é a sede do município; depósitos arenosos, que são áreas grandes com solo exposto e sem vegetação, com o processo de erosão acelerado; campo, que é constituído de vegetação rasteira típica do oeste do Rio Grande do Sul; lavoura que são as plantações e cultivos agrícolas em estágio avançado presentes no município; e mata, que é constituída de capões e matas ciliares ao longo do município. Já nos mapas dos anos 2001 e 2016 foram classificadas as

REVISTA, GE
(ं) PPGEO Programa de Pós-Graduação em Geografia uffff 
seis classes acima citadas e mais a classe de silvicultura que é a plantação de árvores destinadas à produção de madeira, carvão vegetal e celulose que passou a existir posteriormente ao ano de 1986 no município de Cacequi.

No software ENVI Classic foram coletadas amostras conhecidas de cada classe nas imagens de cada ano estudado. Então, foram classificadas de forma supervisionada, pelo método Maxver, no mesmo software de acordo com seu espectro de reflectância igual ou semelhante, individualizando os pixels da imagem.

O método Maxver considera a ponderação das distâncias entre médias dos níveis digitais das classes, utilizando parâmetros estatísticos. Para que a classificação por máxima verossimilhança seja precisa o suficiente, é necessário um número razoavelmente elevado de "pixels", para cada classe. As amostras coletadas na imagem definem o diagrama de dispersão das classes e suas distribuições de probabilidade, considerando a distribuição de probabilidade normal para cada classe, utilizado para classificar o pixel em diferentes classes de acordo com a sua reflectância.

Após esta etapa, foram classificados e agrupados os espectros de reflectância semelhantes ou iguais em polígonos, gerando assim uma base de dados. Esta base de dados foi validada através da análise do índice Kappa, que compara a classificação gerada pelo software com as amostras definidas pelo usuário. Essas amostras são consideradas reais devido à aquisição feita pelo usuário ter como base os levantamentos de campo, e a análise sobre a imagem. Desta forma é obtido o grau de confusão do software na classificação, que é representado pelos valores do índice Kappa, apresentados na tabela 1. Os valores variam de de 0 a 1, sendo que quanto mais próximo a 1 menor a confusão do software e melhor a acurácia dos dados.

TABELA 1

Índice Kappa e Acurácia das classificações realizadas.

\begin{tabular}{|c|c|c|}
\hline Ano & Índice Kappa & Acurácia \\
\hline $\mathbf{1 9 8 6}$ & 0,9345 & $94,43 \%$ \\
\hline $\mathbf{2 0 0 1}$ & 0,9044 & $91,80 \%$ \\
\hline $\mathbf{2 0 1 6}$ & 0,9482 & $95,52 \%$ \\
\hline
\end{tabular}

Fonte: Elaborado pelos Autores (2019)

Quando validados os dados, foram obtidos ótimos índices Kappa e de acurácia e, portanto, os mesmos foram exportados para o SIG ArcGIS 10.1 onde foi realizada a edição final dos mapas.

REVISTA, GEQGRAFIA
PPPGEO Programa de Pós-Graduação
em Geografia ufff 


\section{Resultados}

De acordo com a metodologia de trabalho foram comparados os mapas de uso e ocupação do município de Cacequi, com um recorte espacial de 30 anos, analisados os anos de 1986, 2001 e 2016. No ano de 1986 observou-se um grande predomínio da classe de lavouras, como é possível observar na Figura 2.

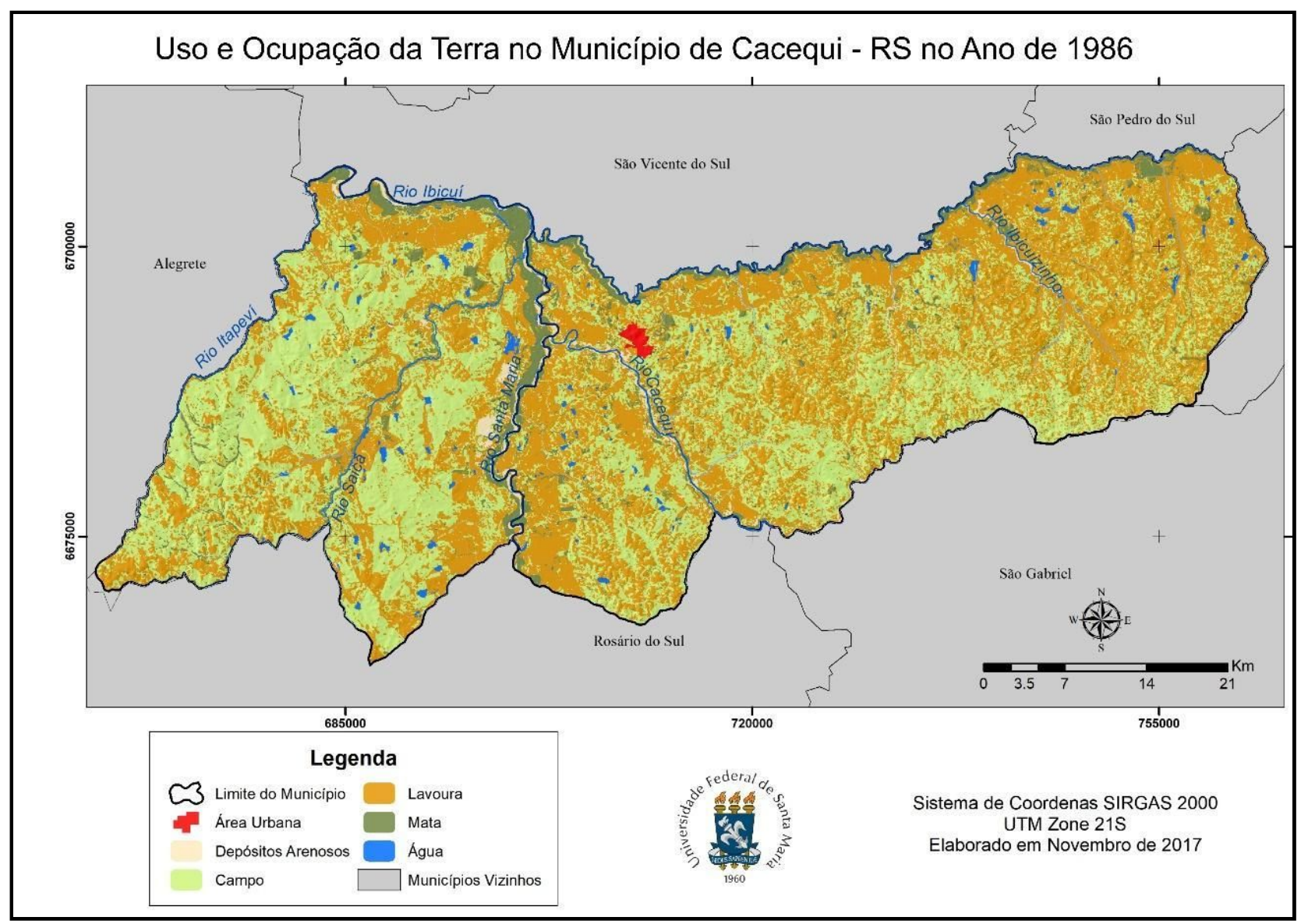

Figura 2 - Mapa de Uso e Ocupação da Terra em Cacequi no Ano de 1986.

Fonte: Elaborado pelos autores (2019).

Referente ao ano de 1986 a classe de lavoura representa 48,91\% da área total. Estas lavouras estão distribuídas por todo o município, com maior concentração nas várzeas dos rios com a produção de arroz. Outra área com grande presença de lavouras é na porção leste do município, onde as colinas são utilizadas para a produção de soja, milho e trigo, na forma de grandes áreas e algumas pequenas lavouras de mandioca, e outros cultivos voltados para a subsistência. 
Este uso intenso do solo na porção leste de Cacequi, onde as litologias são bastante friáveis e altamente erodíveis, acaba intensificando o processo de dissecação das encostas, principalmente nas épocas de entressafra e acarretando o assoreamento dos rios à jusante, conforme pode se observar pelos elevados valores de área de Depósitos Arenosos no ano de 1986 correspondendo a $1,7 \%$ da área de estudo.

Os Depósitos Arenosos estão concentrados próximos aos leitos dos rios de maior volume, como os rios Santa Maria, Cacequi e Ibicuí. Estes depósitos são formados pelo material transportado dos rios, formando bancos de areia nas margens. Outra situação que é possível observar em Cacequi são bancos de areia de meandros abandonados formando extensas áreas de acumulação de areia, como é perceptível na margem esquerda do rio Santa Maria.

A segunda classe que mais predomina em Cacequi no ano de 1986 é a de Campos, caracterizada pela vegetação rasteira para o pastoril do gado de corte e de ovelhas. O Oeste do estado do Rio Grande do Sul possui uma característica histórica de criação de gado, desta forma em Cacequi $41,49 \%$ do município é destinado para este uso.

As áreas de Campo estão concentradas na porção Oeste da área de estudo, próximo aos rios Itapeví e Saicã, se caracterizando como uma importante atividade econômica no município, desde as suas origens. Outro fator relacionado a esta atividade é a presença de barragens e represamentos de água, destinados para a dessedentação animal, que estão representados no mapa pela classe de Água.

No ano de 1986 a classe de Água estava presente em 1,15\% do município, e representa além dos barramentos de água, os principais canais de drenagem. As áreas de maior concentração de água no ano de 1986 eram na porção oeste, onde havia maior concentração de campos.

A área urbana está localizada na porção central do município, próximo ao rio Cacequi e representa $0,20 \%$ da área total. Situa-se em uma área de transição de colinas para a planície do Rio Cacequi e Ibicuí.

Em $6,65 \%$ do território estão presentes as matas, constituída principalmente por matas ciliares, e alguns capões de mata nas áreas mais úmidas, tendo em vista a vegetação mais baixa característica da região, descrita por Alves (2008) como predominantemente constituída por gramíneas e outras plantas herbáceas. Destacam-se as maiores concentrações de mata nas margens dos rios Santa Maria e Ibicuí, com grandes áreas de preservação da mata ciliar.

Após 15 anos, no ano de 2001, foi possível observar mudanças na dinâmica da ocupação de Cacequi. Neste ano a classe que mais foi observada foram os Campos, estando presentes em $1367,99 \mathrm{~km}^{2}$, ou $58,51 \%$ da área, como é possível observar no mapa da Figura 3.

REVISTA, GEQGRAFIA
(ं) PPGEO Programa de Pós-Graduação em Geografia ufff 


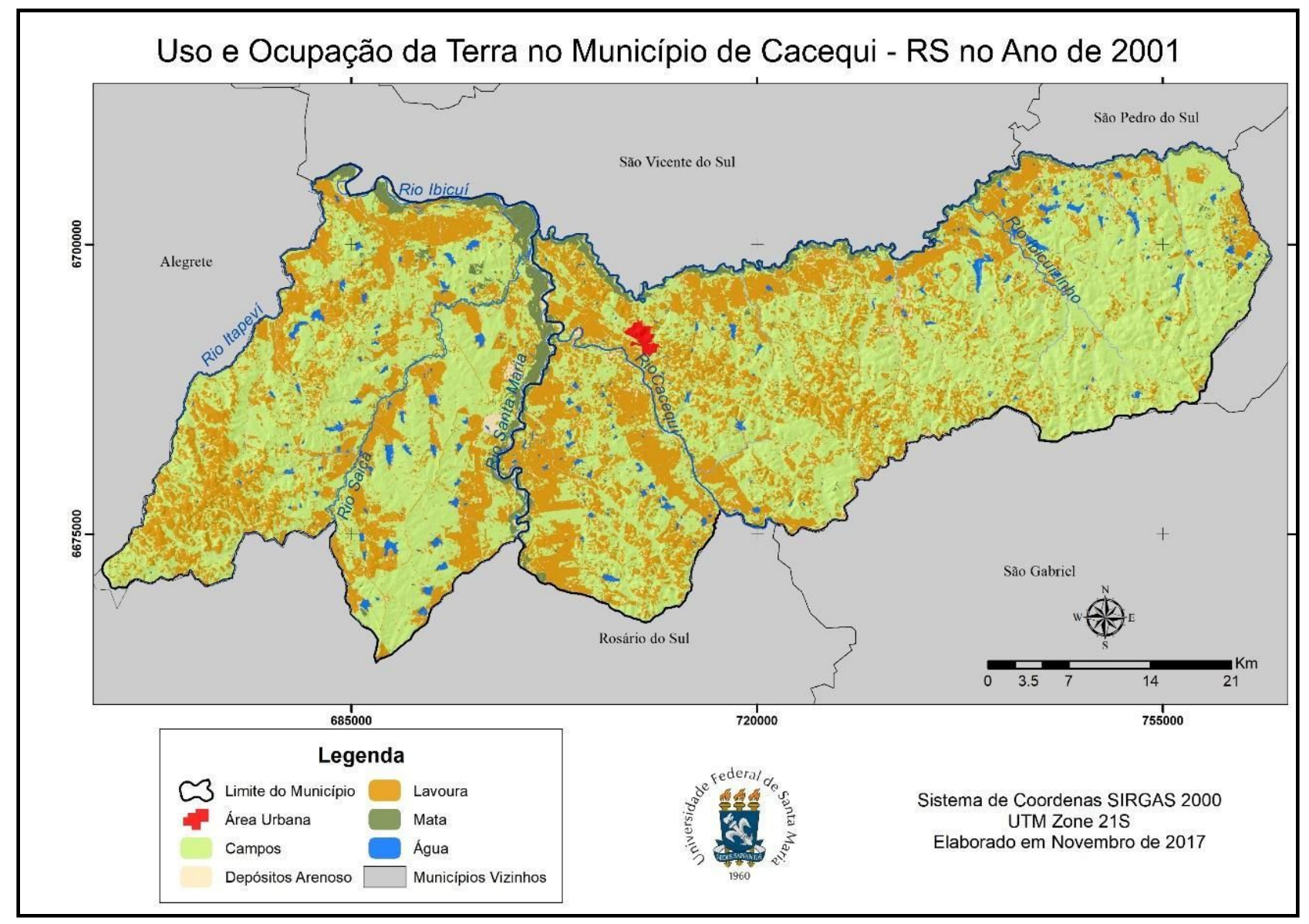

Figura 3 - Mapa de Uso e Ocupação da Terra de Cacequi no Ano de 2001.

Fonte: Elaborado pelos autores (2019).

As áreas de campo estão dispersas por todo o município, porém é possível observar no mapa acima que os campos avançaram sobre áreas que anteriormente eram de lavouras, principalmente no leste do município. Isto se deve principalmente pela mecanização do campo.

Nas décadas de 1970 e 1980 o Brasil e o Rio Grande do Sul passavam pela mecanização do campo, aumentando a área plantada devido a facilidade do plantio, principalmente com a introdução das monoculturas como a da soja. De acordo com Souto (1985) nas décadas de 60 e 70 verificou-se um estímulo governamental acentuado, através de linhas de credito, para atividade agropecuárias, o que trouxe facilidade na aquisição de insumos e equipamentos agrícolas. Influenciados pela sucessão trigo/soja que permitia o uso intensivo das máquinas, os agricultores ampliaram suas áreas de lavoura até o limite de suas propriedades.

Este fenômeno fez com que crescesse neste período a área de lavouras, porém esta euforia inicial foi combatida pelo trabalho pouco lucrativo no campo devido aos solos poucos férteis, industrialização, e consequente urbanização e êxodo rural, bem como a capacidade de regeneração dos nutrientes do solo foram afetadas, diminuindo ainda mais a produtividade. 
Desta forma, nas décadas seguintes no município de Cacequi houve uma diminuição das lavouras, representando em $2001,34,61 \%$ da área total, frente aos quase $50 \%$ de 1986 . A maior parte das lavouras neste ano estão localizadas nas áreas próximas aos canais de drenagem que é característico da produção de arroz irrigado. Outra pequena concentração está nas colinas da porção leste e no extremo sudoeste do município, onde há uma maior produção de soja.

Os Depósitos Arenosos diminuíram em relação ao ano de 1986. No ano de 2001 representava $1,45 \%$ da área total, estando concentrados nos bancos de deposição das principais drenagens.

A classe de Água apresentou um aumento de 84,57\% passando de 26,78 km² em 1986 para $49,44 \mathrm{~km}^{2}$ em 2001. Isto se deve pelo fato da classe de Água estar vinculada à dessedentação animal e houve aumento da área de campos, portanto a existência de reservatórios de água foi maior no ano de 2001.

A classe de Mata apresentou uma significativa diminuição (cerca de $52 \%$ da área em relação à 1986), pois devido ao mais intenso cultivo de arroz nas margens dos rios de maior vazão houve uma supressão da mata ciliar, acarretando na diminuição da área de mata, que em 2001 representava $3,11 \%$. É importante destacar a supressão da mata ciliar nas margens do rio Saicã, no oeste do município, onde em 1986 era bastante perceptível uma mata ciliar e já no ano de 2001 não havia mais, representando o avanço das lavouras nas margens dos rios.

A área urbana do município se manteve estável, representando apenas 0,19\% da área total do município de Cacequi.

No último ano analisado, o ano de 2016, é possível perceber uma manutenção dos campos como a classe predominante na área de estudo (Figura 4) apesar da diminuição da área total, equivalente em 2016 a 52,38\% do município. Os campos estão localizados principalmente entre os rios Saicã e Santa Maria (Figura 5), e ainda, nas áreas mais altas da porção leste e oeste do município. 


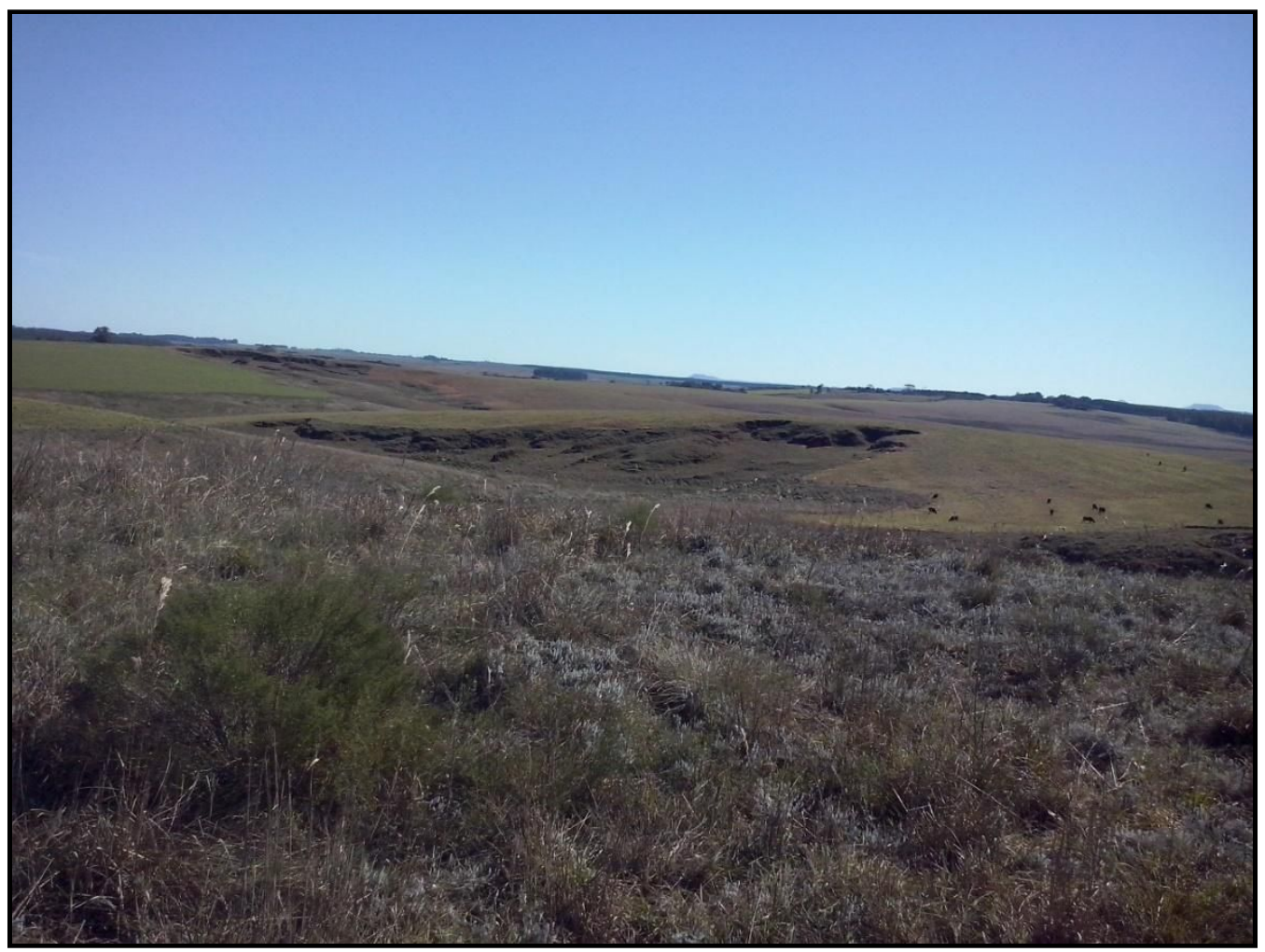

Figura 4 - Áreas de campo nativo para o pastoreio do gado no município de Cacequi Fonte: Os autores (2019)

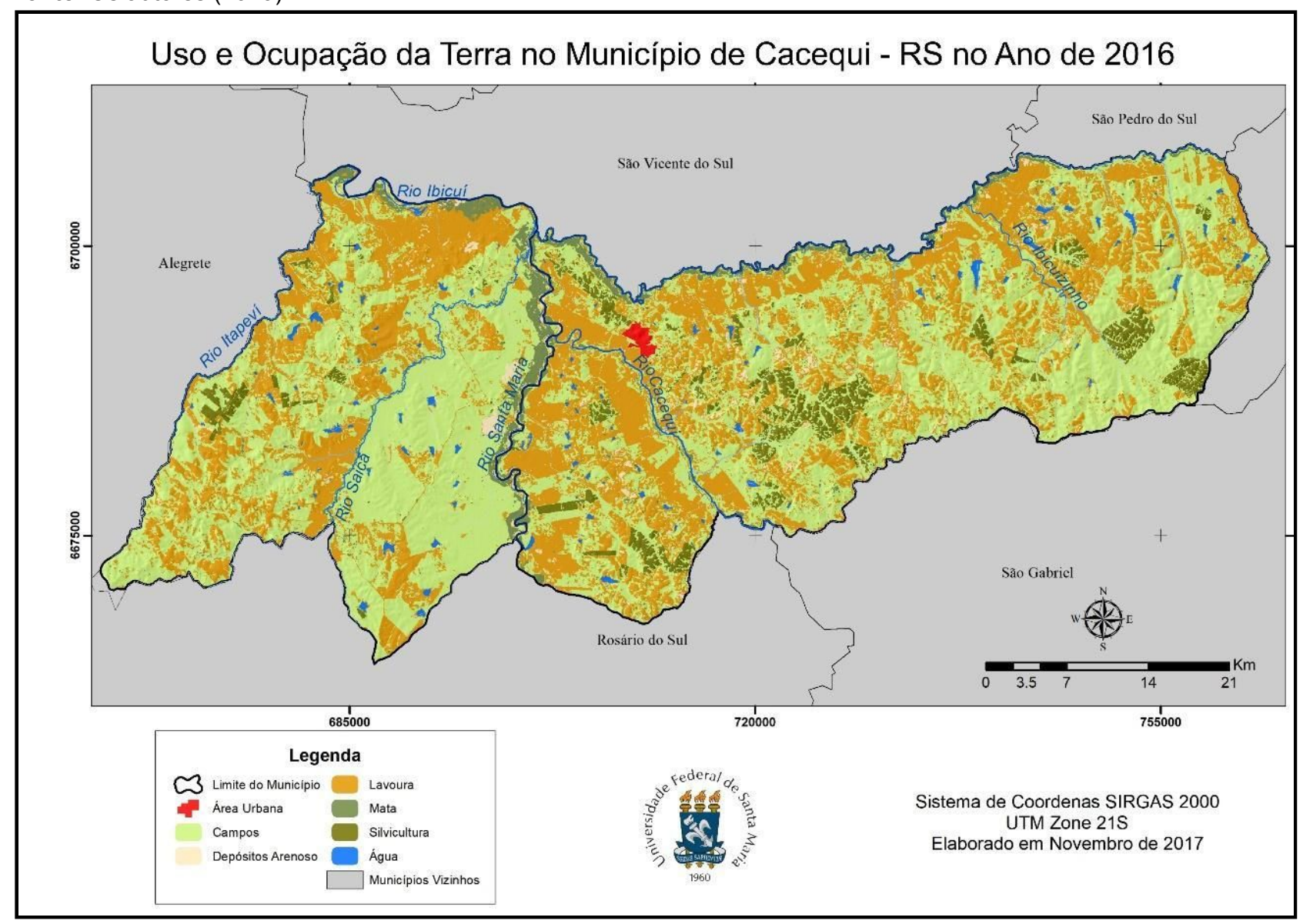

Figura 5 - Mapa de Uso e Ocupação da Terra de Cacequi no Ano de 2016.

Fonte: Elaborado pelos autores (2019).

REVISTA ${ }^{D E}$ GE $\phi$ GRAFIA

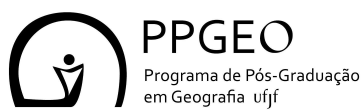

Programa de Pós-Graduação

ISSN: 2236-837X44

V. 9, n. 1, 2019 
Esta diminuição das áreas de campo se deve principalmente pela implementação de uma nova cadeia produtiva em Cacequi, a silvicultura. De acordo com Slongo (2018) as florestas plantadas visam garantir o suprimento de matéria-prima para as indústrias de papel e celulose; madeira para a construção civil e usos nas propriedades rurais; compensados, lâminas e painéis para o setor moveleiro; carvão vegetal e lenha para produção de energia, entre outros usos.

Segundo Silva (2012) a plantação de eucaliptos para a produção de celulose surgiu nos últimos anos, com destaque após incentivos governamentais a partir do ano de 2004, como uma alternativa de uso da terra de grande retorno econômico para as áreas pouco férteis de solos arenosos da região oeste do rio Grande do Sul.

No ano de 2016 a silvicultura (Figura 6) correspondia a 4,33\% da área de Cacequi, marcando a presença desta nova cadeia produtiva no município. A silvicultura se localiza principalmente nas áreas de colinas de arenito eólico, que possuem grande incidência de processos erosivos acelerados, portanto, esta se torna uma alternativa de uso para estas áreas pouco produtivas.

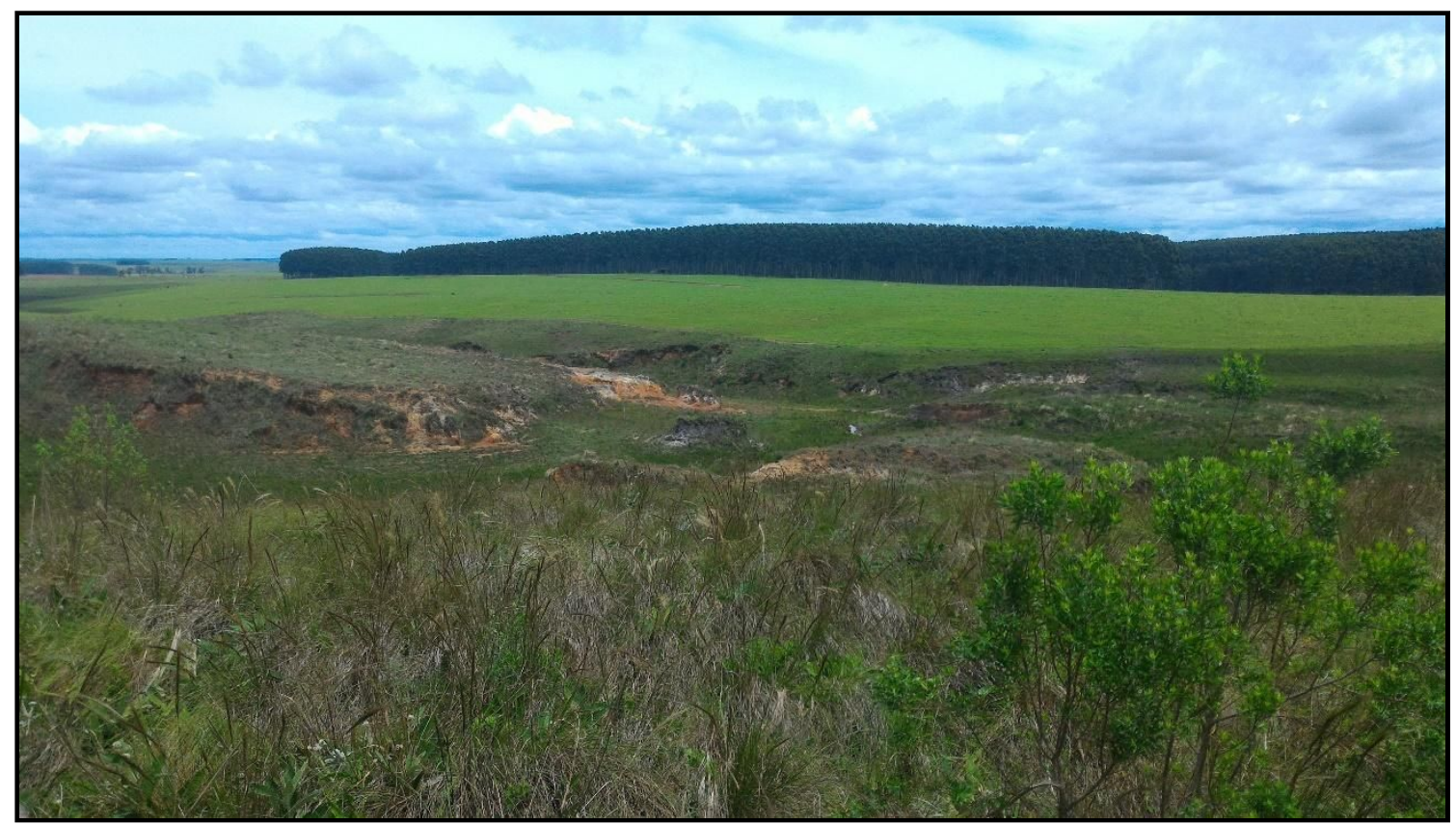

Figura 6 - Plantação de eucaliptos no município de Cacequi.

Fonte: Os autores (2019).

As áreas de água, assim como as áreas de campo, tiveram um pequeno decréscimo na área total, o que era $49,44 \mathrm{~km}^{2}(2,11 \%)$ em 2001 , passou a ser $27,6 \mathrm{~km}^{2}(1,18 \%)$ em 2016 , totalizando uma diminuição de mais de $40 \%$ da área da classe de Água. 
Estando presente em $37,42 \%$ do município, a classe de Lavouras obteve um pequeno aumento em relação a análise do ano de 2001 (+8,52\%), mostrando um pequeno avanço das áreas de lavouras nas áreas de colinas e nas áreas de colinas suaves, no interflúvio dos rios Santa Maria e Cacequi.

Em resposta ao aumento das lavouras houve também um incremento na área de depósitos arenosos, que passaram a representar $1,53 \%$ da área total. A relação da área de lavouras e dos depósitos arenosos, representados na Figura 7, durante o período estudado é bastante significativa, como é possível observar na Tabela 2, que apresenta a área das duas classes, e, quando calculado o Coeficiente de Correlação de Pearson obtém-se um valor de 0,996. Esta correlação se deve pelo fato do maior revolvimento do solo e período de solo exposto nas áreas de lavoura aumentar a quantidade de material erodido. Em consequência disto os rios recebem mais sedimentos e há um aumento de seus bancos de deposição.

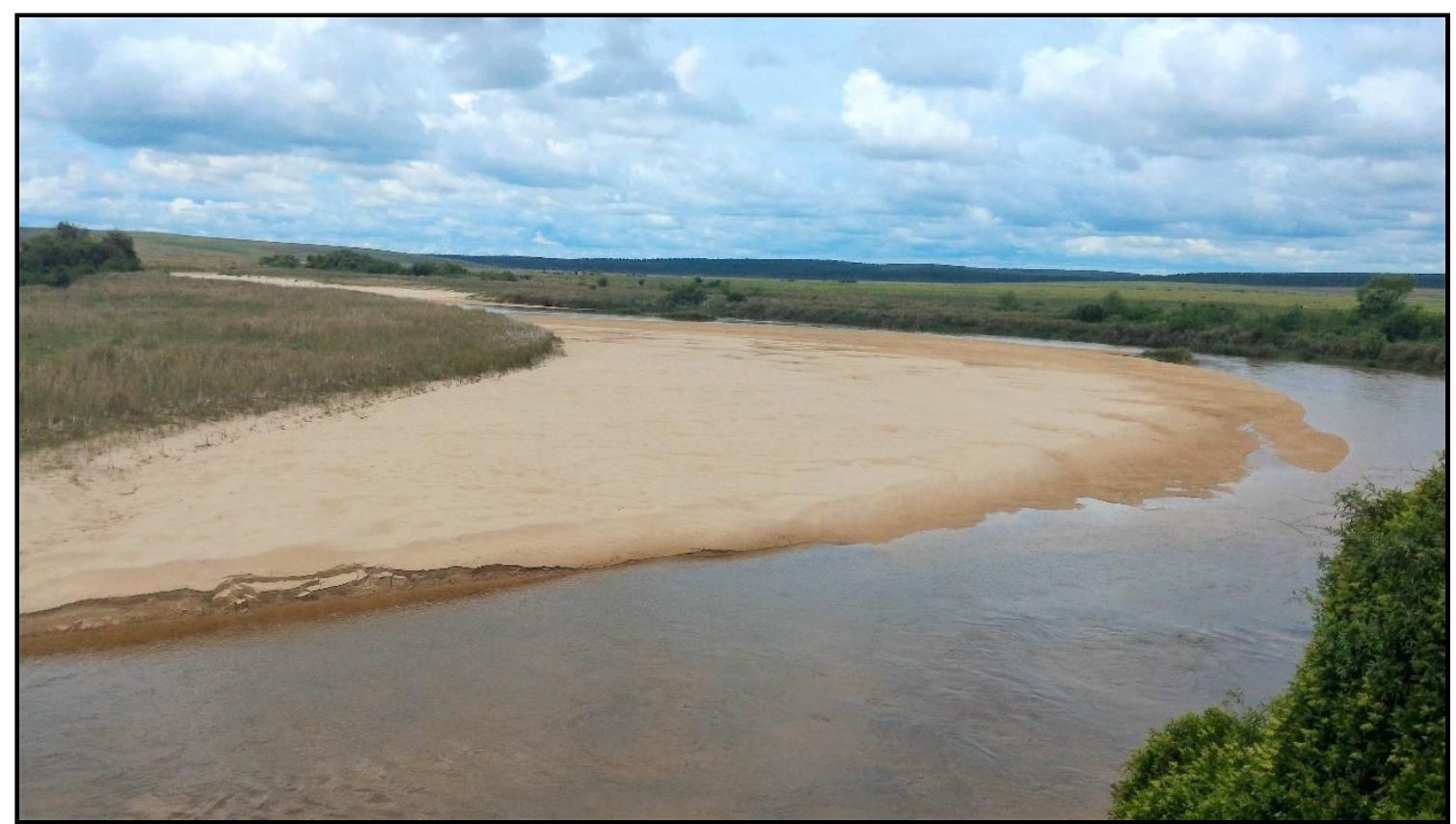

Figura 7 - Depósitos Arenosos associados aos bancos de deposição do rio Areal do Paredão, afluente do Rio Cacequi, município de Cacequi.

Fonte: Os autores (2019)

\section{TABELA 2}

Comparação da Área de Lavoura e Depósitos Arenosos na série histórica de Cacequi.

\begin{tabular}{cccc}
\hline Classe & 1986 & 2001 & 2016 \\
\hline
\end{tabular}




\begin{tabular}{|c|c|c|c|}
\hline Lavoura & $1.143,5 \mathrm{~km}^{2}$ & $806,26 \mathrm{~km}^{2}$ & $874,94 \mathrm{~km}^{2}$ \\
\hline $\begin{array}{c}\text { Depósitos } \\
\text { Arenosos }\end{array}$ & $39,73 \mathrm{~km}^{2}$ & $34,04 \mathrm{~km}^{2}$ & $35.68 \mathrm{~km}^{2}$ \\
\hline
\end{tabular}

No ano de 2016 as áreas de Mata apresentam novamente uma diminuição na área total representando $2,97 \%$ da área. Esta diminuição gradual da área de mata, conforme exposto no gráfico da Figura 8, deixa evidente as consequências de uma apropriação antrópica inadequada, suprimindo a mata ciliar para a produção agrícola e acarretando no aumento do assoreamento dos rios.

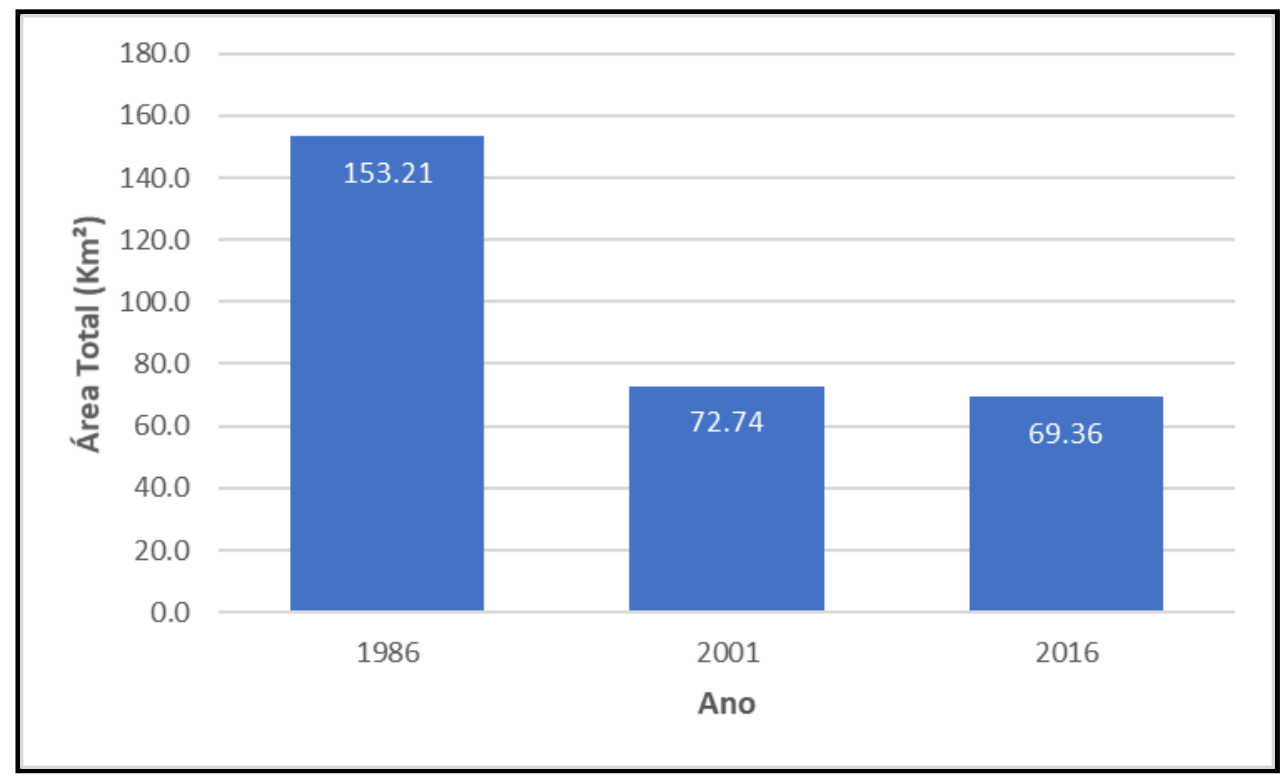

Figura 8 - Evolução da Área Total $\left(\mathrm{km}^{2}\right)$ da classe Mata no município de Cacequi entre os anos de 1986 e 2016.

Fonte: Elaborado pelos autores (2019)

De modo geral, pode-se observar durante o período analisado duas mudanças significativas no uso da terra de Cacequi. Em um primeiro momento uma ocupação majoritariamente de lavouras, causada pela mecanização do campo, com grandes áreas de depósitos arenosos, sinalizando a erosão acentuada do solo e o assoreamento dos rios. Em seguida uma substituição da lavoura pelos campos, como forma de uso econômico das áreas do município tendo em vista a pouca fertilidade do solo na região, acarretando em menor produtividade.

E por fim, no ano de 2016 já é possível vislumbrar uma nova cadeia produtiva no município que tenta ocupar áreas de pouca fertilidade do solo e ainda minimizar a intensidade dos processos erosivos através da plantação de florestas de eucaliptos. 


\section{Considerações Finais}

Através da realização do estudo da série histórica do município de Cacequi foi possível identificar a sua dinâmica, através da troca de cultivos e de formas de uso com o passar dos anos. A perspectiva temporal permitiu observar que o espaço está em constante modificação e a ação antrópica sobre o meio vai interferir nos processos naturais do relevo.

Em Cacequi pode-se constatar que a sua vocação para uso da terra é de pecuária, com extensos campos nativos para o pastoreio do gado bovino e do rebanho ovino. Porém, na década de 1980 houve uma mudança nesta dinâmica com a expansão das áreas de lavoura, movida pela mecanização do campo e introdução de novas culturas e posteriormente, como visto na análise do ano de 2016, uma nova troca de cultivo, com a introdução de espécies exóticas para a extração da celulose.

Essas dinâmicas na ocupação do território e modificações na paisagem geram mudanças na dinâmica superficial, acarretando em estabilização ou intensificação dos processos erosivos, dependendo do tipo de uso da terra, tendo em vista que o município possui litologias muito friáveis e processos erosivos superficiais em grande quantidade.

O uso de imagens de satélite e das ferramentas de geoprocessamento se mostraram de grande importância para a análise da dinâmica de ocupação do município de Cacequi, visto a precisão e velocidade na obtenção de resultados.

Esta análise temporal do uso da terra torna evidente a necessidade de planejamento no ordenamento territorial, pois um dos principais fatores condicionantes para a ocorrência ou intensificação dos processos erosivos é a forma de apropriação do solo, através de seu uso e da cobertura vegetal. Ainda é importante destacar que o presente estudo torna possível outros trabalhos de cunho ambiental na região.

\section{Agradecimentos}

Os autores agradecem à Coordenação de Aperfeiçoamento de Pessoal de Nível Superior (CAPES) e o Conselho Nacional de Desenvolvimento Científico e Tecnológico (CNPq) pelo financiamento da pesquisa e à Universidade Federal de Santa Maria (UFSM) pelo apoio. 


\section{Referências}

ALVES F. S.; Estudos Fitogeográficos na Bacia Hidográfica do Arroio Lajeado Grande - Oeste do RS. Dissertação de Mestrado, UFSM, 2008.

CARRARO, C.C. Mapa Geomorfológico do Estado do Rio Grande do Sul. FAPERGS - UFRGS/Instituto de Geociências. 1974, 1: 1.000.000.

GLOBAL VISUALIZATION VIEWER (GLOVIS). Disponível em <https://glovis.usgs.gov/app?fullscreen=1>. Acessado em outubro de 2019.

SILVA, M. D.; Os Cultivos Florestais do Pampa, no Sul Do Rio Grande do Sul: Desafios, Perdas e Perspectivas Frente Ao Avanço de Novas Fronteiras Agrícolas. Revista Floresta. Curitiba, PR, v. 42, n. 1, p. 215 - 226, jan./mar. 2012.

SLONGO, D. L.; Sistema de Produção Vegetal: Silvicultura. EMATER - RS. Disponível em: <http://www.emater.tche.br/site/area-tecnica/sistema-de-producao-vegetal/silvicultura.php\#.Wm8ZoKinHIU>. Acessado em 29 de janeiro de 2018.

SOUTO, R. Deserto: Uma Ameaça! Secretaria de Agricultura do RS, DRNR, Diretoria Geral, Porto Alegre, 1985.

SOUZA, A. C.; FACCO, D.; PIRES, C. A.; Mapeamento Da Dinâmica Do Uso E Cobertura Da Terra No Município De Pinhal Grande - RS. Anais... XXVI Congresso Brasileiro de Cartografia. Gramado, RS, 2014.

SOUZA, J. R.; REIS, L. N. G. Mapeamento e Análise do Uso dos Solos no Município de Ibiá-MG Utilizando o software SPRING 5.1.8: análise da dinâmica agropecuária. OBSERVATORIUM: Revista Eletrônica de Geografia, v.3, n.8, p.141-163, dez. 2011.

SUERTEGARAY, D. M. A. O Rio Grande do Sul Descobre os Seus "Desertos". Ciência e Ambiente. Santa Maria: Editora da Universidade UFSM. V.11, 1995. p. 33 - 52.

TEOTIA, H. S.; RIBEIRO, G. N.; FRANCISCO, P. R. M. Integração do sensoriamento remoto e sistema de informações geográficas (SIG) para identificação, mapeamento e classificação do uso da terra e cobertura vegetal numa parte do Agreste Paraibano no Brasil. Anais... XIV Simpósio Brasileiro de Sensoriamento Remoto. Natal, p. 4489-4496, abril de 2009. 